\title{
Continuous Low-Level Glial Cell Line-Derived Neurotrophic Factor Delivery Using Recombinant Adeno-Associated Viral Vectors Provides Neuroprotection and Induces Behavioral Recovery in a Primate Model of Parkinson's Disease
}

\author{
Andisheh Eslamboli, ${ }^{1}$ Biljana Georgievska, ${ }^{2}$ Rosalind M. Ridley, ${ }^{1}$ Harry F. Baker, ${ }^{1}$ Nicholas Muzyczka, ${ }^{3}$ \\ Corinna Burger, ${ }^{3}$ Ronald J. Mandel, ${ }^{4}$ Lucy Annett, ${ }^{5}$ and Deniz Kirik ${ }^{2}$ \\ ${ }^{1}$ Department of Experimental Psychology, University of Cambridge, Cambridge CB2 3EB, United Kingdom, ${ }^{2}$ Wallenberg Neuroscience Center, Division of \\ Neurobiology, Biomedical Center A11, 22184 Lund, Sweden, Departments of ${ }^{3}$ Molecular Genetics and Microbiology and ${ }^{4}$ Neuroscience, McKnight Brain \\ Institute and Gene Therapy Center, College of Medicine, University of Florida, Gainesville, Florida 32610, and ${ }^{5}$ Psychology Department, University of \\ Hertfordshire, Hatfield, Hertfordshire AL10 9AB, United Kingdom
}

The therapeutic potential of glial cell line-derived neurotrophic factor (GDNF) for Parkinson's disease is likely to depend on sustained delivery of the appropriate amount to the target areas. Recombinant adeno-associated viral vectors (rAAVs) expressing GDNF may be a suitable delivery system for this purpose. The aim of this study was to define a sustained level of GDNF that does not affect the function of the normal dopamine (DA) neurons but does provide anatomical and behavioral protection against an intrastriatal 6-hydroxydopamine (6-OHDA) lesion in the common marmoset. We found that unilateral intrastriatal injection of rAAV resulting in the expression of high levels of GDNF (14 ng/mg of tissue) in the striatum induced a substantial bilateral increase in tyrosine hydroxylase protein levels and activity as well as in DA turnover. Expression of low levels of GDNF ( $0.04 \mathrm{ng} / \mathrm{mg}$ of tissue), on the other hand, produced only minimal effects on DA synthesis and only on the injected side. In addition, the low level of GDNF provided $\sim 85 \%$ protection of the nigral DA neurons and their projections to the striatum in the 6-OHDA-lesioned hemisphere. Furthermore, the anatomical protection was accompanied by a complete attenuation of sensorimotor neglect, head position bias, and amphetamine-induced rotation. We conclude that when delivered continuously, a low level of GDNF in the striatum (approximately threefold above baseline) is sufficient to provide optimal functional outcome.

Key words: gene therapy; 6-hydroxydopamine; adeno-associated virus; monkey; GDNF; dopamine

\section{Introduction}

Glial cell line-derived neurotrophic factor (GDNF) is a potential treatment for Parkinson's disease (PD), recently evaluated in Phase I clinical trials. Gill et al. (2003) showed therapeutic effects of continuous infusion of GDNF into the putamen, although in a recent news release, Amgen (Thousand Oaks, CA) reported that in a Phase II study, 34 patients with advanced PD who received continuous infusion of GDNF into the putamen showed no clinical improvement after 6 months of treatment, despite evidence of altered brain function (http://www.amgen.com/news/viewPR.

Received Aug. 18, 2004; revised Nov. 29, 2004; accepted Nov. 29, 2004.

This work was supported by grants from the Wellcome Trust (A.E.), Medical Research Council (MRC) UK (R.M.R. and H.F.B.), Swedish Research Council (K2003-33P-14788-01A and K2002-33X-03874-30C to D.K. and B.G.), and National Institute of Neurological Disorders and Stroke (NS 36302 to R.J.M., N.M., and C.B.). A.E., R.M.R., and H.F.B. are members of the MRCCentre for Behavioral and Clinical Neurosciences at Cambridge University. We thank Ulla Jarl for technical assistance and the Powell Gene Therapy Center Vector Core for production of the vectors used in this study. We thank Pia Wiekop for performing the HPLC analysis.

Correspondence should be addressed to Andisheh Eslamboli, Department of Experimental Psychology, Innes Building, School of Veterinary Medicine, Madingley Road, Cambridge CB3 0ES, UK. E-mail: ae228@cam.ac.uk. DOI:10.1523/JNEUROSCI.4421-04.2005

Copyright $\odot 2005$ Society for Neuroscience $\quad$ 0270-6474/05/250769-09\$15.00/0 jsp?id = 585632). Nutt et al. (2003), using monthly intracerebroventricular injections of GDNF, found no beneficial effects, and Kordower et al. (1999) found significant side effects using this procedure, although there was no evidence of penetration of GDNF into the appropriate target areas. These studies demonstrate that if GDNF is to have a clinical application, development of methods for delivery of appropriate amounts of GDNF to target areas is required.

Because PD is a progressive disorder, the long-term efficacy of GDNF treatment depends on its prolonged delivery (Kirik et al., 2004). Sustained delivery (measured at 3 weeks, 10 weeks, and 6 months after injection) has been obtained by direct intracerebral injection of GDNF using recombinant lentiviral or adenoassociated viral vectors (rAAVs) and has been evaluated in intact and lesioned rodents (Choi-Lundberg et al., 1997; Mandel et al., 1997; Deglon et al., 2000; Kirik et al., 2000a; Rosenblad et al., 2000a; Georgievska et al., 2002, 2004) and in primates (Kordower et al., 2000; Eslamboli et al., 2003b). These studies show at least two distinct effects of GDNF on dopamine (DA) neurons. GDNF has a pharmacological effect on neurotransmission in intact adult DA neurons by, for example, increasing DA turnover and regu- 
lating expression of tyrosine hydroxylase (TH) (Kirik et al., 2000a; Kordower et al., 2000; Rosenblad et al., 2003; Georgievska et al., 2004). GDNF also induces regeneration and sprouting in injured DA neurons (Kirik et al., 2000a; Georgievska et al., 2002), although the pharmacological effect can appear in the absence of regeneration and sprouting (Kirik et al., 2000a; Georgievska et al., 2004).

Here, we compared biochemical effects after rAAV-mediated expression of either a high or a low level of GDNF on the intact DA system in monkeys to define a level of continuous GDNF expression that did not have substantial pharmacological effects on normal DA neurons. GDNF expression at $0.04 \mathrm{ng} / \mathrm{mg}$ of tissue did not affect normal DA neurotransmission, so an rAAV expressing this amount was used in a recently developed intrastriatal 6-hydroxydopamine (6-OHDA) lesion (LES) model of PD in monkeys (Eslamboli et al., 2003a). This low level of GDNF expression in the striatum provided substantial protection of the nigrostriatal DA system and functional recovery on a range of behavioral measures.

\section{Materials and Methods}

Monkeys and experimental design. Experimental procedures were performed in accordance with the United Kingdom Animals (Scientific Procedures) Act (1986). Thirty-one laboratory-bred adult common marmosets (Callithrix jacchus), 12 females and 19 males, were used. The monkeys weighed 321-431 g and were 23-51 months of age at the start of the experiment.

For experiment 1 , three groups of monkeys were used to determine the effects of sustained expression of a low or high level of GDNF on the intact primate nigrostriatal dopamine system: (1) group GDNF-low $(n=$ 5 ) received an rAAV expressing a low level of GDNF and green fluorescent protein (GFP); (2) group GDNF-high $(n=4)$ received an rAAV expressing a high level of GDNF only; (3) group GFP $(n=4)$ received an rAAV expressing GFP only. Twelve weeks after the vector surgery, the monkeys were killed, and their brains were removed for biochemical analysis.

In experiment 2, each monkey was assigned to one of three groups on the basis of their preoperative behavioral scores: (1) group GDNF plus LES $(n=6)$ initially received the GDNF-low vector; (2) group GFP plus LES $(n=6)$ initially received the GFP vector and served as a lesion/vector control. Eight weeks later, both groups received an intrastriatal 6-OHDA lesion on the same side as the vector surgery; (3) group INTACT $(n=6)$ did not receive any vector or the 6-OHDA lesion. This group served as the nonlesioned control for behavioral measurements. Monkeys in groups GDNF plus LES, GFP plus LES, and INTACT were assessed behaviorally before any surgery, 7 weeks after the vector surgery (i.e., just before the 6-OHDA lesion), and 2, 7, 12, and 17 weeks after the 6-OHDA surgery. When behavioral testing was complete, the GDNF plus LES and GFP plus LES monkeys were perfused, and their brains were removed and examined histologically.

Recombinant $A A V$ vector preparation. The three vectors (see supplemental Fig. 1, available at www.jneurosci.org as supplemental material) were constructed and titered at the University of Florida Gene Therapy Center Vector Core (Gainesville, FL) using the methods detailed previously (Conway et al., 1997; Zolotukhin et al., 1999; Xu et al., 2001). The GFP vector consisted of a chicken $\beta$-actin promoter (CBA), which is a cytomegalovirus enhancer with a downstream chicken $\beta$-actin/rabbit $\beta$-globin hybrid intron driving humanized enhanced GFP. The GDNFhigh vector had a chicken $\beta$-actin promoter with a cytomegalovirus enhancer with a downstream chicken $\beta$-actin/rabbit $\beta$-globin hybrid intron that drove the production of the transgene. This construct included the woodchuck posttranslational regulatory element downstream of the GDNF gene. The GDNF-low vector consisted of the same CBA promoter with a deletion of $693 \mathrm{bp}$ in the intron and an internal ribosomal entry site between the GDNF and the GFP genes. The GDNF-low vector had a final infectious titer of $4.4 \times 10^{11} \mathrm{IU} / \mathrm{ml}$, the GFP vector had a final infectious titer of $1.2 \times 10^{11} \mathrm{IU} / \mathrm{ml}$, and the GDNF-high had a final titer of $4.0 \times 10^{11} \mathrm{IU} / \mathrm{ml}$. Given the accuracy of the titering methods, these vectors had essentially equal titers (Burger et al., 2004).

Wild-type AAV-2 virus is not associated with any known human disease, making it an excellent tool for gene therapy in the brain. In addition, in the recombinant AAV-2 vectors used in this study, all the viral genome except the inverted terminal repeats has been replaced with the transgene of interest. Thus, no viral proteins are expressed by the transduced cells, making it very unlikely for any immune reaction to take place in the injected monkeys. Furthermore, Peden et al. (2004) have recently used the same vector construct and showed that the vector injection alone did not provoke infiltration of blood cells or activation of astrocytes or microglial cells in the brain beyond what can be seen with injection of sterile saline solution.

Surgery. For all surgery, monkeys were anesthetized with $0.5 \mathrm{ml}$ of alphaxalone-alphadolone (Saffan; $12 \mathrm{mg} / \mathrm{ml}$, i.m.; Schering-Plough, Welwyn Garden City, UK). A supplementary dose of 0.2-0.3 ml of Saffan was given during surgery, if necessary. After each surgery, the monkeys were given an analgesic (Finadyne; $0.1 \mathrm{mg} / \mathrm{kg}$, s.c.; Schering-Plough Animal Health, Mildenhall, UK).

In experiments 1 and 2 , the vectors were injected unilaterally into the striatum. The injections were made with a 28 gauge $10 \mu$ l Hamilton needle at a rate of $0.7 \mu \mathrm{l} / \mathrm{min}$. Six injections of $2 \mu \mathrm{l}$ (i.e., a total of $12 \mu \mathrm{l}$ ) were made in the striatum. After each injection, the needle was kept in place for an additional 3 min before being withdrawn. The injections were made using coordinates derived from the stereotaxic atlas of Stephan et al. (1980) at the following sites: (1) anteroposterior (AP) 6.0, lateral (LAT) 6.9, ventral (V) 10.0; (2) AP8.0, LAT6.2, V9.5; (3) AP8.0, LAT2.8, V11.7; (4) AP10.0, LAT5.3, V9.4; (5) AP10.0, LAT2.4, V11.4; (6) AP12.0, LAT3.0, V10.5.

In experiment 2, the monkeys in group GDNF plus LES and group GFP plus LES underwent the intrastriatal 6-OHDA surgery 8 weeks after the vector surgery. In a previous study, we found that nine intrastriatal injections of $8 \mu \mathrm{g}$ each of 6-OHDA resulted in behavioral deficits that recovered by 10 weeks after lesion (Eslamboli et al., 2003a). In the hope of achieving longer-lasting behavioral deficits, twice as many injections were made into the striatum between coordinates AP6.5 to AP13.5, LAT2.3 to LAT6.7, and V8.5 to V13.2 (i.e., a total of 18 injections of $8 \mu \mathrm{g}$ each of 6-OHDA). The injections were made ipsilateral to the vector injections. 6-OHDA HCl ( $4 \mathrm{mg} / \mathrm{ml}$ free base weight dissolved in $0.01 \%$ ascorbate/saline) was freshly prepared and stored on ice immediately before use. Injections of $2 \mu \mathrm{l}$ each were made using a 28 gauge $10 \mu \mathrm{l}$ Hamilton syringe at a rate of $0.5 \mu \mathrm{l} / \mathrm{min}$. After each injection, the needle was left in place for $2 \mathrm{~min}$ before withdrawal.

Biochemical tissue analysis for experiment 1. For biochemical analysis, the monkeys were premedicated with $0.05 \mathrm{ml}$ of ketamine (Vetalar; 100 $\mathrm{mg} / \mathrm{ml}$, i.m.; Shering-Plough), killed with $0.6 \mathrm{ml}$ of sodium pentobarbitone $(200 \mathrm{mg} / \mathrm{ml}$, i.p. $)$, and the brains were removed immediately after death. Viewed from above, the corpus callosum was bisected, and the cerebral hemispheres were rolled apart to expose the caudate and putamen, which were removed by blunt dissection, and each was chopped and separated into three equal parts. To dissect the substantia nigra (SN; pars compacta and pars reticulata), the cerebral peduncles were identified on the ventral surface of the brainstem, and the appropriate area dorsal to these landmarks was removed by blunt dissection. All samples were weighed, placed immediately on dry ice, and subsequently stored at $-70^{\circ} \mathrm{C}$ until analyzed. The SN sample and one of the caudate and putamen samples from each side of each monkey were processed for determination of GDNF levels using an ELISA, whereas the remaining samples were used for HPLC, Western blots, and TH activity measurements.

For GDNF ELISA, samples were sonicated in a homogenization buffer (50 mu Tris, pH 7.4, $150 \mathrm{~mm} \mathrm{NaCl}, 1 \%$ Triton X-100, $10 \mu \mathrm{g} / \mathrm{ml}$ aproptinin, $1.7 \mu \mathrm{g} / \mathrm{ml}$ phenylmethylsulfonyl fluoride, $1.0 \mu \mathrm{g} / \mathrm{ml}$ leupeptin, 1.0 $\mu \mathrm{g} / \mathrm{ml}$ pepstatin) at a tissue concentration of $30 \mathrm{mg} / \mathrm{ml}$ and were centrifuged at $20,000 \times g$ for $10 \mathrm{~min}$ at $4^{\circ} \mathrm{C}$. GDNF protein levels were determined on homogenates using an ELISA kit (G7621; Promega, Madison, $\mathrm{WI}$ ) according to the manufacturers recommendations, as used previously in rodent studies (Georgievska et al., 2004).

TH enzyme activity was determined according to Reinhard et al. (1986). Striatal tissue was sonicated in $10 \mu \mathrm{l} / \mathrm{mg}$ of homogenization 
buffer (20 mм MES, pH 6.1, 0.2\% Triton) and centrifuged at 20,000 $\times g$ for $10 \mathrm{~min}$ at $4^{\circ} \mathrm{C}$. The supernatant was collected and divided into two parts; one was used for TH enzyme activity assay and the other for Western blot analysis (see below). A mixture of $4 \mu \mathrm{l}$ of L- $\left[3,5-{ }^{3} \mathrm{H}\right]$-tyrosine (Amersham Biosciences, Little Chalfont, UK), $100 \mu \mathrm{l}$ of $500 \mu \mathrm{M}$ L-tyrosine (Sigma, St. Louis, MO), $500 \mu \mathrm{l}$ of $200 \mathrm{~mm} \mathrm{MES,} \mathrm{pH} \mathrm{6.1,} 12 \mu \mathrm{l}$ of catalase (12,690 U; Sigma), and $688 \mu \mathrm{l}$ of distilled $\mathrm{H}_{2} \mathrm{O}$ was prepared. Ten microliters of the supernatant were added to $65 \mu \mathrm{l}$ of this mixture together with $25 \mu \mathrm{l}$ of cofactor biopterin $(0.6 \mathrm{mg} / \mathrm{ml}$, dissolved in 3 $\mathrm{mg} / \mathrm{ml}$ DTT; RBI, Natick, MA). Samples were then incubated for $20 \mathrm{~min}$ at $37^{\circ} \mathrm{C}$. The reaction was stopped with $1.0 \mathrm{ml}$ of charcoal $\mathrm{HCl}$, and the samples were then centrifuged at 20,000 $\times g$ for $15 \mathrm{~min}$. One hundred microliters of supernatant were added to $5 \mathrm{ml}$ of scintillation liquid (Instagel Plus; Packard Bioscience, Groningen, The Netherlands). TH activity was expressed as the number of counts per minute per microgram of protein (1214 Rackbeta; LKB-Wallac, Gaithersburg, MD). Protein concentration was determined using the Bradford method (Bio-Rad, Hercules, CA).

$\mathrm{TH}$ protein levels were determined using Western blot analysis, as described previously (Georgievska et al., 2004). Homogenates were diluted 1:1 with Laemmli solution buffer (Bio-Rad) containing 2.5\% mercaptoethanol (Sigma) and were frozen. Four micrograms of protein from each sample were heated at $95-100^{\circ} \mathrm{C}$ for $5 \mathrm{~min}$ and then centrifuged before being loaded onto a 4-20\% SDS-PAGE gel (Criterion precast gel; Bio-Rad) and run for $2 \mathrm{~h}$ at $150 \mathrm{~V}$. The gels were electroblotted onto a polyvinylidene difluoride membrane (Bio-Rad) and run for $2 \mathrm{~h}$ at $50 \mathrm{~V}$. The membrane was probed with a primary antibody against TH (1:1000; Pel-Freez, Rogers, AR) overnight. The membrane was then incubated in anti-rabbit horseradish peroxide-linked secondary antibody (Amersham Biosciences) and then in hyperfilm ECL solution (Amersham Biosciences) for $1 \mathrm{~min}$. The membrane was then exposed to ECL film, and the film was developed. For each animal, the intact and the injected sides were run on the same blots in duplicate. The density of each band was measured using ImageJ software version 1.32 (a public domain product distributed by the National Institutes of Health, Bethesda, MD; http:// rsb.info.nih.gov/ij/), and the data were expressed as percentage of untreated side.

Levels of DA and its metabolites 3,4-dihydroxyphenylacetic acid (DOPAC) and homovanillic acid (HVA) were determined using reversephase HPLC (Lotharius et al., 2002). The tissues of each brain were homogenized in $1 \mathrm{ml}$ of $0.1 \mathrm{~N}$ perchloric acid, and after centrifugation at $14,000 \times g$ for $30 \mathrm{~min}, 200 \mu \mathrm{l}$ of the supernatant was filtered through a $0.22 \mu \mathrm{m}$ glass filter. Ten or $20 \mu \mathrm{l}$ of the filtered supernatant was examined for DA and its metabolites. For the HPLC, a YMCaqua C18 column $(3 \times$ $100 \mathrm{~mm}$; particle size, $5 \mu \mathrm{m}$ ) was used (YMC Europe GmbH, Schermbeck, Germany). Detection was made using an ESA (Zoeterwoude, The Netherlands) electrochemical detector set at a potential of $300 \mathrm{mV}$ versus an $\mathrm{Ag} / \mathrm{AgCl}$ reference electrode. The mobile phase was delivered by an LC 10 AD Shimadzu (Tokyo, Japan) HPLC pump at $0.5 \mathrm{ml} / \mathrm{min}$ and contained $0.051 \mathrm{M} \mathrm{NaH}_{2} \mathrm{PO}_{4} \mathrm{H}_{2} \mathrm{O}$ with $0.92 \mathrm{~mm}$ octanesulphonic acid, 0.048 mM $\mathrm{Na}_{2}$ EDTA, and $11 \%$ methanol, adjusted to $\mathrm{pH} 3.7$ with $1 \mathrm{M}$ phosphoric acid and was degassed using an on-line degasser. Data were acquired using the Shimadzu (chromatographic CLASS LC-10) software package.

Behavioral tests for experiment 2 . The data were collected by an experimenter (A.E.) who was unaware of the group identity of the vectortreated monkeys. The tasks used were the two-tubes choice task and the six-tubes search task (see Fig. 1 for details). Both these tasks assess spatial neglect within the contralesional hemifield of the monkey's peripersonal sensorium, because the monkey is free to use either arm and to orient itself in front of the apparatus. The two-tubes choice task assesses ipsilesional bias by measuring which of a pair of adjacent tubes, presented at different places in peri-personal space and both containing a reward, is chosen. The six-tubes search task assesses ipsilesional bias by measuring the time the monkey takes to find the single reward hidden in one of six tubes presented in a horizontal array in front of the monkey. The twotube task measures pure choice behavior, whereas the six-tube task assesses choice behavior and voluntary motor action including praxis, because it measures time to complete the task. Measures were also taken of the monkeys' head position bias and amphetamine-induced rotation (see Fig. 1 for details).

Monkeys were also tested on the hill staircase task (Marshall et al., 2002), in which the monkey is required to reach through vertical slots in a Plexiglas screen to retrieve rewards that are placed on the steps of two staircases that ascend toward the center of the device. The slots are positioned laterally so that the monkey has to reach with the left arm into its left hemispace and the right arm into its right hemispace. Monkeys with unilateral 6-OHDA lesions take longer to retrieve rewards using the contralesional arm on the contralesional side (Milton et al., 2004). This task is a measure of total contralesional disability comprising motor disability and sensory neglect.

Histology and morphometric analysis for experiment 2. After completing their last behavioral tests, the monkeys in groups GDNF plus LES and GFP plus LES from experiment 2 were premedicated with $0.05 \mathrm{ml}$ of ketamine (Vetalar; $100 \mathrm{mg} / \mathrm{ml}$, i.m.; Shering-Plough), deeply anesthetized with $0.6 \mathrm{ml}$ of sodium pentobarbitone $(200 \mathrm{mg} / \mathrm{ml}$, i.p.), and perfused transcardially with $300 \mathrm{ml}$ of $0.1 \mathrm{M}$ PBS, pH 7.4, followed by $300 \mathrm{ml}$ of $4 \%$ paraformaldehyde in PBS. The brains were removed and placed in $4 \%$ paraformaldehyde solution for $24 \mathrm{~h}$, transferred to $30 \%$ sucrose in PBS for $4 \mathrm{~d}$ at $4^{\circ} \mathrm{C}$, and then cut at $40 \mu \mathrm{m}$ using a freezing stage microtome.

Immunohistochemistry was performed as described by Eslamboli et al. (2003b). Sections were treated for 10 min with $10 \%$ methanol/3\% hydrogen peroxide in PBS and preincubated in the appropriate blocking serum for $1 \mathrm{~h}$. The sections were then incubated overnight at room temperature in the primary antibody. The antibodies used were rabbit anti-TH antibody (1:250; Pel-Freeze), rabbit anti-vesicular monoamine transporter-2 (VMAT2) antibody (1:2000; Chemicon, Temecula, CA), rabbit anti-GFP (1:20,000; Abcam, Cambridge, UK), and goat antiGDNF antibody (1:2000; R\&D Systems, Minneapolis, MN). Appropriate secondary antibodies (goat anti-rabbit and horse anti-goat; 1:200 dilution; Vector Laboratories, Burlingame, CA) directed against the species in which the primary antibody was raised were used in all cases. Sections were incubated for $1 \mathrm{~h}$ in a streptavidin-biotin-peroxidase kit (Vector Laboratories). The reactions were visualized using 3,3-diaminobenzidine as a chromagen. Sections were mounted on $1 \%$ gelatin-coated microscope slides, dehydrated in ascending alcohol concentrations, cleared in xylene, and coverslipped using Depex mountant.

Unbiased stereological estimation of the total number of cells in the $\mathrm{SN}$ was made using the optical fractionator for both $\mathrm{TH}$-immunoreactive (TH-IR) and VMAT2-immunoreactive (VMAT2-IR) sections as described previously (Eslamboli et al., 2003b). Typically, 9 or 10 sections, which covered the entire SN, were sampled at $40 \times$ magnification for both TH-IR and VMAT2-IR using the Computer Assisted Stereological Toolbox system developed by Olympus (Danmark A/S; Ballerup, Denmark). The size of the counting frame was chosen so that 100-200 cells would be counted per $\mathrm{SN}$ for each immunoreactive measure. The total number of cells was estimated by the optical fractionator formula (West, 1999).

Striatal TH-IR and VMAT2-IR fiber density in the caudate nucleus and putamen was determined by optical densitometry readings measured using ImageJ software version 1.32. Images were captured from nine rostro-caudal levels over the whole striatum (AP 13.5 to AP 5.5) (Stephan et al., 1980) using a constant illumination table and a highresolution digital camera (ProgRes C14; Jenoptik, Jena, Germany). Readings were corrected for nonspecific background density, measured from a completely denervated part of the striatum, and averaged across all sections, as described previously (Kirik et al., 2000a).

Statistical analysis. Postlesion data were analyzed for within- and between-group effects using a repeated-measures ANOVA. Prelesion comparisons between groups as well as histological and biochemical data were made using factorial ANOVAs. Where there were significant interactions, post hoc comparisons were made using $t$ tests with Bonferroni corrections.

\section{Results}

Effects of high- versus low-level rAAV-mediated GDNF delivery on intact nigrostriatal DA neurons (experiment 1)

The GDNF levels obtained using the GDNF-low vector were $0.040 \pm 0.002(\mathrm{SEM}) \mathrm{ng} / \mathrm{mg}$ of tissue in the injected striatum, 
Table 1. GDNF protein levels (in nanograms per milligram of tissue) as measured by ELISA from striatum and SN, 12 weeks after vector injection in experiment 1

\begin{tabular}{llll}
\hline & \multicolumn{2}{c}{ Striatum } & \multicolumn{2}{c}{ Substantia nigra } & \multicolumn{1}{c}{ Uninjected side } \\
\cline { 2 - 4 } & Uninjected side & Injected side & $0.074 \pm 0.013^{* *}$ \\
GDNF-high & $0.079 \pm 0.023$ & $13.780 \pm 2.5^{* *}$ & $0.017 \pm 0.001$ \\
GDNF-low & $0.015 \pm 0.007$ & $0.040 \pm 0.002^{* * *}$ & $0.879 \pm 2.052^{* *}$ \\
GFP & $0.013 \pm 0.003$ & $0.012 \pm 0.002$ & $0.023 \pm 0.002$ \\
\hline
\end{tabular}

All values are \pm SEM. Repeated-measures ANOVA on all three groups showed significant group $\times$ area $\times$ side interaction $\left(F_{(2,10)}=7.4 ; p=0.011\right)$. Post hoc comparisons were made with the GFP group in each area on each side using $t$ test with Bonferroni correction. ${ }^{* *} p<0.01 ;{ }^{* * *} p<0.001$.

Table 2. TH enzyme activity and levels of DA and its metabolites in the injected striatum, 12 weeks after vector injection in experiment 1

\begin{tabular}{|c|c|c|c|c|c|c|}
\hline & \multicolumn{3}{|l|}{ Uninjected side } & \multicolumn{3}{|l|}{ Injected side } \\
\hline & GFP & GDNF-Iow & GDNF-high & GFP & GDNF-Iow & GDNF-high \\
\hline TH activity (counts/min $/ \mu \mathrm{g}$ ) & $2883 \pm 306$ & $2906 \pm 277$ & $10086 \pm 312^{* * *}$ & $2715 \pm 240$ & $3865 \pm 234^{*}$ & $18628 \pm 381^{* * *}$ \\
\hline DA (pmol/mg of tissue) & $253.0 \pm 22.0$ & $207.0 \pm 21.0$ & $103.6 \pm 54.7^{*}$ & $253.0 \pm 2$ & $237.0 \pm 15$ & $64.2 \pm 10.5^{* * *}$ \\
\hline DOPAC (pmol/mg of tissue) & $4.4 \pm 0.4$ & $3.6 \pm 0.4$ & $120.5 \pm 17.2^{* * *}$ & $4.4 \pm 0.8$ & $4.55 \pm 0.5$ & $186.1 \pm 66.1^{*}$ \\
\hline HVA (pmol/mg of tissue) & $21.6 \pm 1.2$ & $19.9 \pm 1.9$ & $236.5 \pm 63.8^{* *}$ & $21.6 \pm 1.5$ & $31.5 \pm 1.7$ & $270.7 \pm 40.3^{* * *}$ \\
\hline DOPAC/DA & $0.018 \pm 0.003$ & $0.018 \pm 0.002$ & $1.810 \pm 0.45^{* * *}$ & $0.017 \pm 0.003$ & $0.019 \pm 0.002$ & $2.890 \pm 0.77^{* *}$ \\
\hline HVA/DA & $0.087 \pm 0.008$ & $0.097 \pm 0.005$ & $3.080 \pm 0.52^{* * *}$ & $0.085 \pm 0.005$ & $0.136 \pm 0.014$ & $4.570 \pm 1.07^{* * *}$ \\
\hline
\end{tabular}

All values are \pm SEM. Repeated-measures ANOVAs across each biochemical marker showed a significant group effect in all cases, significant side effects for TH activity, DOPAC/DA, and HVA/DA, and a significant group $\times$ side interaction for TH activity, DOPAC/DA, and HVA/DA. Post hoc $t$ test with Bonferroni corrections were performed to compare each GDNF group to the GFP group on the same side. ${ }^{*} p<0.05$; ${ }^{* *} p<0.01$; ${ }^{* * *} p<0.001$.

which was threefold to fourfold higher than that found in the contralateral striatum or the rAAV-GFP-injected animals. There was no significant change in GDNF levels in the ipsilateral SN. Using the GDNF-high vector, $13.8 \pm 2.5$ (SEM) ng/mg of tissue was detected in the injected striatum, which was $>100$-fold higher than that found in the contralateral striatum and $>1000$ fold higher than that found in rAAV-GFP-injected animals. In addition, a very high level of GDNF $[6.9 \pm 2.1$ (SEM) ng/mg of tissue] was also detected in the ipsilateral $\mathrm{SN}$, and some increase in the level of GDNF was found in the contralateral SN (Table 1).

Expression of a high level of GDNF (GDNF-high group) produced a 6.8-fold increase in TH activity in the injected striatum and a 2.5-fold increase in the uninjected striatum, compared with levels found in the GFP group (Table 2). TH protein levels in the injected striatum were $83 \%$ higher than in the uninjected striatum, an elevation which matches the $85 \%$ increase in $\mathrm{TH}$ activity in the injected compared with the uninjected striatum (although the GDNF-high vector affected dopaminergic markers in both hemispheres). Tissue DA content was significantly reduced (by $75 \%$ in the injected and $59 \%$ in the uninjected hemisphere), whereas striatal HVA/DA and DOPAC/DA ratios were dramatically increased in the injected (53- and 160-fold, respectively) and uninjected (34- and 100-fold, respectively) hemispheres in the GDNF-high group, suggesting that the very high turnover of DA in the GDNF-high group had reduced the tissue levels of DA.

In contrast, expression of low levels of GDNF produced a smaller $(42 \%)$ but significant increase in the striatal TH activity of the injected side only. Aside from striatal TH activity, no other DA metabolic parameters were altered in the GDNF-low group.

\section{Behavioral effects of continuous expression of low levels of striatal GDNF in the lesioned monkeys (experiment 2)}

Two weeks after the 6-OHDA lesion, the GDNF plus LES and the GFP plus LES groups demonstrated equivalent and substantial behavioral deficits in comparison to the INTACT group on measures of sensorimotor neglect (two-tubes and six-tubes tasks), head position bias, and amphetamine rotation. For the two-tubes task, when the two tubes were located on the lesioned side of the monkeys, both the lesioned groups preferentially chose the reward from the tube which was further away (i.e., more ipsile- sional), whereas INTACT monkeys preferred the closer, contralesional tube (Fig. 1A). For the six-tubes task, both the lesioned groups spent substantially longer than the INTACT group finding the food reward when it was in the most contralesional position (Fig. $1 B$ ). Both lesioned groups had an equivalent and substantial ipsilesional head position bias, in contrast to INTACT monkeys that did not show a side preference (Fig. 1C). After amphetamine challenge, the lesioned groups rotated ipsilesionally over the $30 \mathrm{~min}$ interval in contrast to INTACT monkeys, which did not rotate (Fig. 1D). On the hill staircase task, the GDNF plus LES monkeys took $108 \pm 17$ (SEM) seconds, and the GFP plus LES monkeys took $148 \pm 15$ (SEM) seconds to retrieve all the rewards on the contralesional side using the contralesional arm in comparison to INTACT monkeys that took only $44 \pm 6$ (SEM) seconds $(p<0.05$ for each lesion group relative to INTACT).

Between 7 and 17 weeks after 6-OHDA surgery, a difference in the lesion-induced deficits between the GDNF plus LES monkeys and the GFP plus LES monkeys became apparent (Fig. 1). Seven weeks after the lesion, the GDNF plus LES monkeys were less impaired than the GFP plus LES monkeys on the two-tubes and six-tubes tasks and on head position bias score. By week 17, recovery was complete in the GDNF plus LES monkeys on these tasks, whereas the GFP plus LES monkeys remained impaired. Similarly, the GDNF plus LES monkeys showed substantial amelioration of amphetamine-induced rotation, whereas the GFP plus LES monkeys did not. On the hill staircase task, the GDNF plus LES group recovered more quickly than the GFP plus LES group, reaching normal levels by 7 weeks after the lesion, whereas the GFP plus LES group returned to normal levels by 12 weeks (group by week interaction, $F_{(6,45)}=5.28 ; p<0.001$; confirmed by post hoc analysis).

On tasks requiring skilled performance (two-tubes, six-tubes, and staircase tasks), the monkeys in the GFP plus LES group showed some improvement over time. This was probably as a result of practice, because this group showed less improvement on measures of posture and activity (head bias and amphetamine rotation). The GDNF plus LES group might also have improved somewhat with practice, so the crucial indicator of the efficacy of 


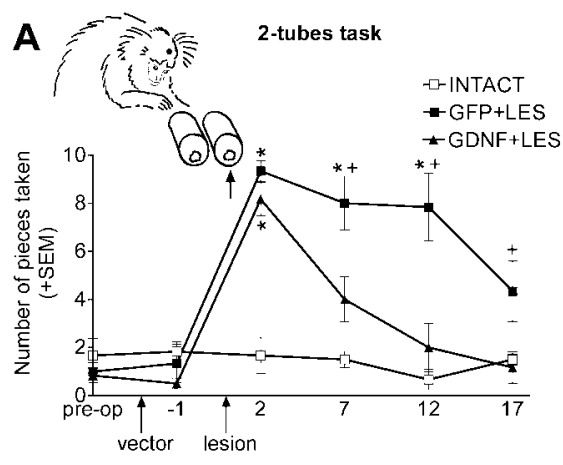

C
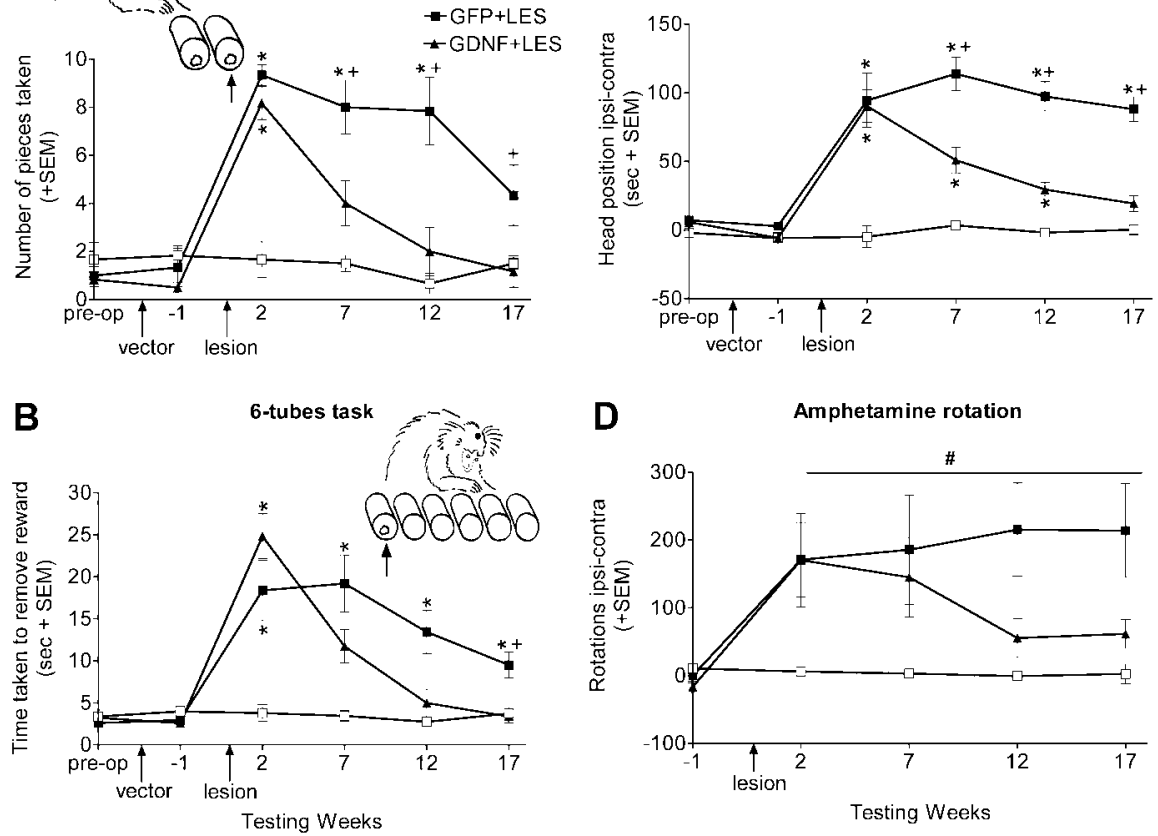

Figure 1. Behavioral measures. $A$, The two-tubes task. On each of 30 trials, each monkey was presented with two tubes that were both baited with a food reward. The tubes were pseudorandomly presented to the front, left, or right of the monkey such that there were 10 trials in each position. The monkey was allowed to remove the food reward from either of the two tubes. Monkeys will usually choose the nearer, more central, tube when the pair of tubes is presented to their left or right and will choose randomly when the tubes are presented centrally. Monkeys with an ipsilesional bias differ from normal monkeys in that they choose the ipsilesional tube of the pair, regardless of the position in which they are presented. This difference is most marked when the tubes are presented on the ipsilesional side, because unlesioned monkeys will choose the nearer tube, and lesioned monkeys will choose the tube which is further away, as illustrated in $A$, which shows the number of pieces retrieved from the further tube. $B$, The six-tubes task. On each of 30 trials, each monkey was presented with a horizontal array of six tubes, one of which contained food reward. Each tube was baited five times in a pseudorandom order. The animal was allowed $30 \mathrm{~s}$ per trial to find the reward. Normal monkeys take very slightly longer to find a reward in an outer tube compared with the time taken to find centrally located rewards. Monkeys with unilateral 6-OHDA lesions take longer to find the reward in any tube but are particularly slow to find the reward when it is in the most contralesional tube (Milton et al., 2004). B shows the time taken to find the reward in the most contralesional tube. C, Head position bias. Each monkey was observed for $180 \mathrm{~s} / \mathrm{d}$ for $3 \mathrm{~d}$. C shows the average number of seconds per day that the monkeys had their heads turned ipsilesionally minus contralesionally. $D$, Amphetamine rotation. Each monkey was videotaped for $30 \mathrm{~min}$, starting $30 \mathrm{~min}$ after injection with amphetamine $(0.5 \mathrm{mg} / \mathrm{kg}$, i.m.; Sigma). D shows average number of ipsilesional minus contralesional $360^{\circ}$ rotations. After 6-0HDA lesions, there were group by week interactions (two-tubes task, $F_{(6,45)}=6.04, p<$ 0.001 ; six-tubes task, $F_{(6,45)}=10.50, p<0.001$; head position bias, $\left.F_{(8,60)}=3.676, p<0.01\right)$. Differences at each time point were compared using Bonferroni corrected $t$ tests. ${ }^{*} p<0.05$ compared with INTACT; ${ }^{+} p<0.05$, GDNF plus LES compared with GFP plus LES. \# indicates that there was a group difference in amphetamine rotation $\left(F_{(2,15)}=5.21 ; p<0.05\right)$. The group by week interaction approached significance $\left(F_{(6,45)}=2.14 ; p=0.07\right)$. The "blobs" on the heads in the diagrams indicate the side of the lesion. The arrows point to the tubes for which data are shown. Error bars represent SEM.

the GDNF lies in the difference in performance between these groups at each time point.

\section{GDNF-induced neuroprotection and regenerative sprouting in the injured nigrostriatal DA system (experiment 2)}

Immunohistochemistry for TH on sections through the SN and basal ganglia of GFP plus LES monkeys demonstrated that the 6-OHDA lesion resulted in a substantial but incomplete reduction (by 63\%) in the number of TH-IR cells in the SN (Fig. 2, Table 3 ) and a reduction in TH-IR fiber density in the caudate (by $54 \%$ ) and putamen (by 50\%) (Fig. 3, Table 3). GDNF gene delivery had a neuroprotective effect against the 6-OHDA lesion. In the lesioned SN, the GDNF plus LES monkeys had only a $16 \%$ reduction in TH-IR cells (Fig. 2, Table 3). Striatal TH-IR fiber innervation was also protected in the GDNF plus LES group. There was a smaller reduction in TH-IR fiber density in the
GDNF plus LES group (44\% reduction in caudate; $13 \%$ in putamen) compared with the reduction in the GFP plus LES monkeys (Fig. 3, Table 3). These findings were confirmed by immunohistochemistry for VMAT2, an additional marker for DA neurons (Table 3 ). Fiber density measures in the unlesioned side of the GDNF plus LES monkeys were very similar to those in the unlesioned side of the GFP plus LES monkeys. The number of cells in the SN in the unlesioned side of the GDNF plus LES monkeys was slightly higher than in the unlesioned side of the GFP plus LES monkeys. The mechanism for this is unclear. Inspection of sections stained with $\mathrm{TH}$ revealed the presence of sprouting from the rescued DA neurons in the GDNF plus LES monkeys, both at the level of SN (Fig. 2C) and in the globus pallidus (Fig. $3 F, I$ )

Figure 4 shows GDNF-IR and GFP-IR staining in basal ganglia in a typical monkey from group GDNF plus LES. Staining was visible in the ipsilesional globus pallidus and ipsilesional subthalamic nucleus. This distribution of staining was unexpected, and levels of GDNF had not been measured in these areas in experiment 1. This distribution was probably a result of anterograde transport of the protein to these regions and increased affinity for the rAAV in these regions in contrast to the striatum (Kirik et al., 2000a). No staining was seen in the SN, ventral tegmental area, or elsewhere, suggesting that the transport of the GDNF was to a large extent anterograde but not retrograde or transynaptic.

Inspection of histology revealed that all detectable injection sites were in the neostriatum. Although, as shown in Figure 4, GDNF staining was robust in striatal efferent structures, GDNF staining was detectable in the striatum but only as very faintly staining and sparsely distributed cell bodies in the injected hemisphere in some GDNF plus LES monkeys. This finding is probably attributable to the transport and secretion of GDNF combined with its known long half-life in vivo. Thus, accumulation of GDNF in striatal efferent structures allowed levels to be detectable via immunohistochemistry. In support of this contention, striatal GDNF levels were elevated above background as measured by ELISA from dissections that excluded efferent anatomical sites.

\section{Discussion}

When GDNF was expressed at a level that was only threefold to fourfold above baseline, there were minimal or no effects on various biochemical measures of DA neurotransmission, whereas expression of a higher level of GNDF significantly altered all DA markers bilaterally. Because the viral titers of the three vectors were very similar, the elevated levels of GDNF (and the changes in dopamine markers) in the contralateral hemisphere, after injection of the high expression vector, are presumably at- 
tributable to substantial spread of the GDNF protein. In view of the potential for deleterious effects of such widespread distribution of high levels of GDNF, we used the low-expressing vector and showed that, although it did not alter the function of intact DA neurons, it could still protect the nigrostriatal DA system from the toxic insult of the intrastriatal 6-OHDA lesion and that it was able to provide a clear benefit in a range of spontaneous and druginduced behavioral tasks.

Neuroprotection of the substantia nigra The ability of GDNF to protect TH-IR cell bodies in the SN after a lesion has been used as the primary outcome measure in several experiments (Beck et al., 1995; Sauer et al., 1995; Tomac et al., 1995; Winkler et al., 1996; Lu and Hagg, 1997). Repeated injections or infusions of human recombinant GDNF protein were found to be more potent than single bolus injections (Sauer et al., 1995; Lu and Hagg, 1997; Rosenblad et al., 2000b). Lu and Hagg (1997) performed a dose-response study using osmotic minipumps to deliver GDNF continuously over 2 weeks and found that $\mathrm{ED}_{50}$ was $\sim 1$ $\mu \mathrm{g} / \mathrm{d}$, whereas maximum protection was achieved at a dose of 3 $\mu \mathrm{g} / \mathrm{d}$. A similar level of protection was achieved by direct injection of viral vectors encoding the GDNF gene (Choi-Lundberg et al., 1997; Mandel et al., 1997; Deglon et al., 2000; Kirik et al., 2000a; Kordower et al., 2000; Georgievska et al., 2002), with expression levels in the $0.2-6.3 \mathrm{ng} / \mathrm{mg}$ tissue range (for review, see Bjorklund et al., 2000). These findings suggested that a low level of GDNF would be sufficient for significant neuroprotection when it is delivered continuously by the transduced cells locally in the brain. However, a dose-response study using viral vectors has never been performed.

In a previous study, we delivered higher levels of GDNF to both the $\mathrm{SN}$ and striatum (using the same vector batch as the GDNF-high vector in experiment 1 of the present study), followed by a 6-OHDA nigro-striatal bundle lesion (Eslamboli et al., 2003b). This lesion is known to lead to a rapid and near-complete destruction of the cell bodies in the $\mathrm{SN}$ and an anterograde degeneration of the ascending fiber bundles. In that experiment, despite widespread and high levels of expression, the protective effects of GDNF were modest both in the cell bodies of the SN and in the striatal fiber terminals (Eslamboli et al., 2003b). In contrast, in the present work, an intrastriatal lesion model was used in which the DA cells of the SN underwent retrograde degeneration, and we found that the GDNF-low vector, which had minimal effects on DA neurotransmission, produced near-complete protection of DA cells.

\section{The state of the TH-IR fiber terminals determines the functional outcome}

Several experiments have shown that even when almost all nigral DA neurons are rescued after a lesion-inducing procedure, marginal, or no, benefits in motor performance in GDNF-treated animals are observed unless striatal fiber terminals are also protected; the best functional recovery is seen when there is prominent TH-positive innervation in the striatum (Winkler et al.,

\section{TH-IR in SN}
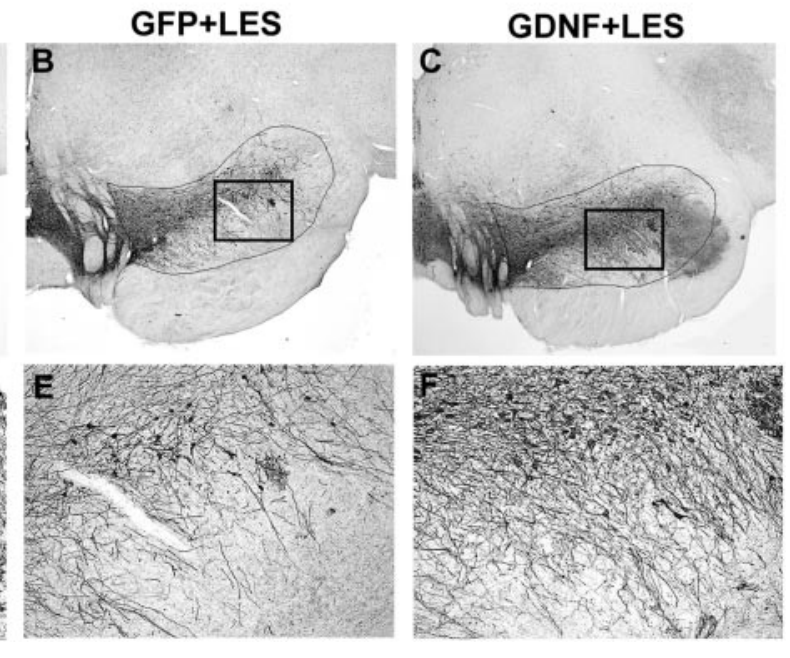

Figure 2. TH-IR staining of the SN (AP 4.5). A, Unlesioned SN. B, Lesioned SN in a monkey from group GFP plus LES showing
substantial reduction in staining. C, Lesioned SN in a monkey from group GDNF plus LES showing partial protection against the 6-0HDA lesion. $D-F$, High-power micrographs taken from $A-C$, respectively, at the locations indicted by the boxes. $E$ shows reduction in TH-IR fibers. F shows substantial protection of the TH-IR fibers in the SN that extend into the SN pars reticulata. SNpc, SN pars compacta; SNpr, SN pars reticulata; VTA, ventral tegmental area; $c p$, cerebral peduncles. Scale bars: (in A) $A-C, 1 \mathrm{~mm}$; (in 1996; Sullivan et al., 1998; Rosenblad et al., 1999; Kirik et al., 2000a,b). Importantly, however, Georgievska et al. (2002) have shown recently that functional recovery could be compromised in lesioned animals when high levels of GDNF were delivered using a lentiviral vector. They showed that GDNF-treated rats may fail to improve behaviorally, despite both nigral DA neurons and their striatal fiber terminals being preserved. At least two mechanisms were identified as potential contributing factors to this outcome: (1) downregulation of TH in preserved DA terminals and (2) aberrant sprouting of TH-positive fibers in output nuclei of the basal ganglia. In a follow-up study, Georgievska et al. (2004) showed that the downregulation of TH was time and dose dependent and appeared to be a compensatory response of nigral DA neurons to an initial enhancement of DA function and the continued presence of high levels of GDNF.

In the present study, we detected prominent fiber sprouting in the globus pallidus and the SN pars reticulata, although comparison between VMAT2- and TH-immunostained sections indicated that there was no effect of the low level of GDNF on TH expression. Because animals treated with low-expression vector showed excellent behavioral recovery, fiber sprouting in GP and SN does not block execution of normal motor behaviors, provided that the striatal DA terminals are preserved and TH expression is not affected. Nonetheless, accumulation of GDNF in the globus pallidus, distant from the injection sites, emphasizes the need for additional investigation before clinical application.

Two weeks after the 6-OHDA lesion, all monkeys were impaired on measures of sensorimotor neglect, body asymmetry, and drug-induced rotation. From 7 weeks after the lesion, the monkeys in group GDNF plus LES began to display a gradual but eventually complete amelioration of all these deficits, whereas the monkeys in group GFP plus LES continued to display deficits on most measures up to the end of the experiment, 17 weeks after the lesion. In the GDNF plus LES group, the timing of recovery was similar for the different behavioral measures, suggesting that the neural mechanisms underlying the behavioral recovery were 
Table 3. Histological markers of effects of lesions and vector treatments in experiment 2

\begin{tabular}{|c|c|c|c|c|}
\hline & \multicolumn{2}{|l|}{ Unlesioned side } & \multicolumn{2}{|l|}{ Lesioned side } \\
\hline & $\begin{array}{l}\text { GFP plus LES } \\
(n=6)\end{array}$ & $\begin{array}{l}\text { GDNF plus LES } \\
(n=6)\end{array}$ & $\begin{array}{l}\text { GFP plus LES } \\
(n=6)\end{array}$ & $\begin{array}{l}\text { GDNF plus LES } \\
(n=6)\end{array}$ \\
\hline \multicolumn{5}{|l|}{ Cell counts } \\
\hline \multicolumn{5}{|c|}{ Substantia nigra } \\
\hline TH-IR & $50,348 \pm 5495$ & $61,424 \pm 4476$ & $\begin{array}{l}18,765 \pm 1222 \\
(37 \%)\end{array}$ & $\begin{array}{l}51,839 \pm 4701^{* * * *} \\
(84 \%)\end{array}$ \\
\hline VMAT2-IR & $48,247 \pm 2679$ & $60,268 \pm 3893^{*}$ & $\begin{array}{l}13,023 \pm 1611 \\
(27 \%)\end{array}$ & $\begin{array}{l}50,565 \pm 3590^{* * *} \\
(84 \%)\end{array}$ \\
\hline \multicolumn{5}{|c|}{ Fiber density (optical density units) } \\
\hline \multicolumn{5}{|l|}{ Caudate } \\
\hline TH-IR & $35.5 \pm 2.7$ & $36.8 \pm 1.2$ & $\begin{array}{l}16.2 \pm 2.0 \\
(46 \%)\end{array}$ & $\begin{array}{l}21.3 \pm 3.0 \\
(56 \%)\end{array}$ \\
\hline VMAT2-IR & $39.5 \pm 4.4$ & $38.5 \pm 2.5$ & $\begin{array}{c}16.7 \pm 1.7 \\
(42 \%)\end{array}$ & $\begin{array}{l}19.3 \pm 2.9 \\
(50 \%)\end{array}$ \\
\hline \multicolumn{5}{|l|}{ Putamen } \\
\hline TH-IR & $35.7 \pm 1.2$ & $35.0 \pm 2.0$ & $\begin{array}{l}17.7 \pm 1.3 \\
(50 \%)\end{array}$ & $\begin{array}{l}30.5 \pm 2.5^{* * *} \\
(87 \%)\end{array}$ \\
\hline VMAT2-IR & $36.7 \pm 5.0$ & $35.8 \pm 3.5$ & $\begin{array}{l}18.5 \pm 1.0 \\
(50 \%)\end{array}$ & $\begin{array}{l}28.0 \pm 3.7^{*} \\
(78 \%)\end{array}$ \\
\hline
\end{tabular}

All values are \pm SEM. Values in parentheses are lesioned side as percentage of unlesioned side in the same group. Separate ANOVAs over the TH-IR and VMAT2-IR cell counts showed significant group $\times$ side interactions in both cases. Post hoc $t$ test showed that the GDNF plus LES group had much higher cell counts than the GFP plus LES group on the lesioned side. There was a small increase in cell counts on the intact side in the GDNF plus LES group. Separate ANOVAs over the TH-IR and VMAT2-IR fiber density showed significant group $\times$ area $\times$ side in both cases. Post hoc $t$ test showed that the GDNF plus LES group had higher density measures than the GFP plus LES group in the putamen on the lesioned side. ${ }^{*} p<0.05 ;{ }^{* * *} p<001$.

\section{TH-IR in Basal Ganglia}

\section{Unlesioned side}
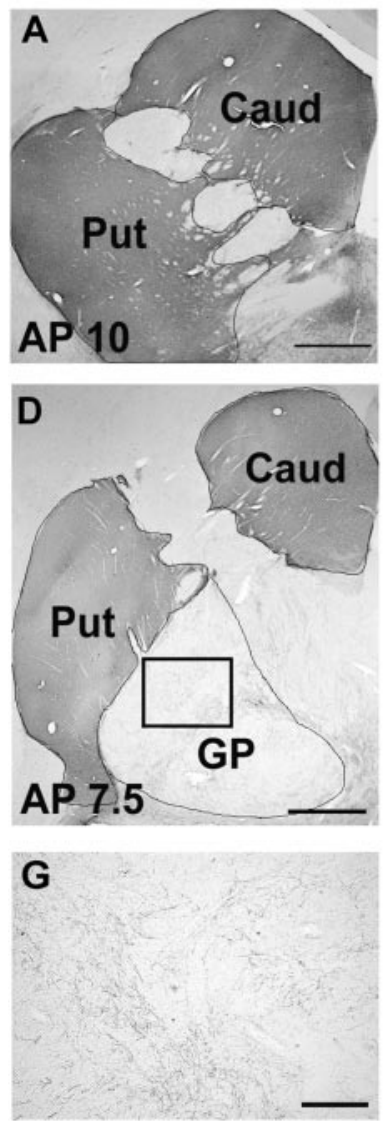

GDNF+LES
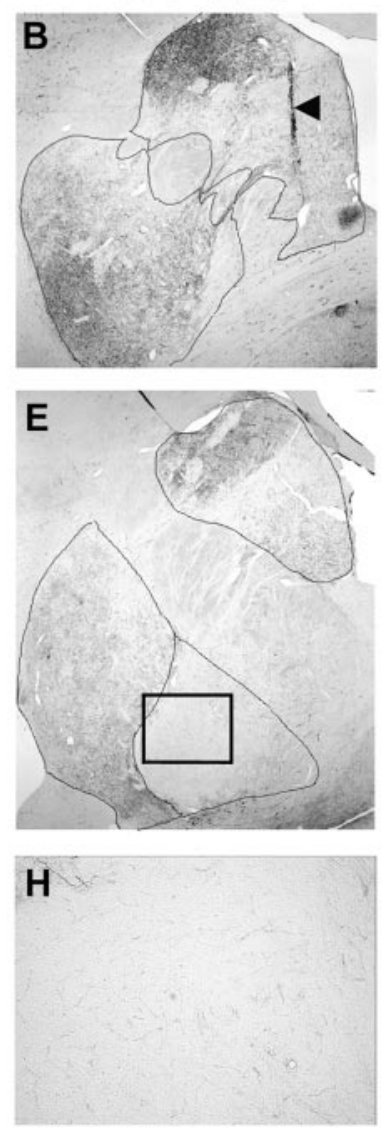
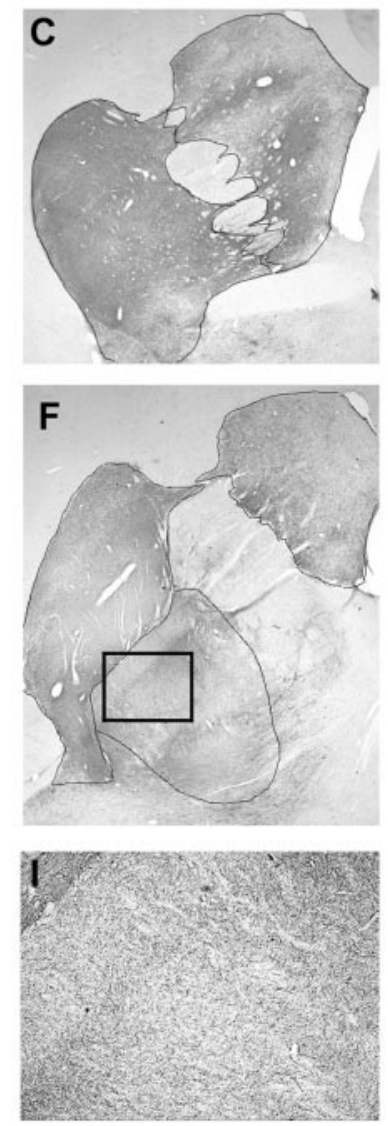

Figure 3. TH-IR staining of the basal ganglia (AP10.0 and 7.5). A, D, Unlesioned basal ganglia. $B, E$, Lesioned basal ganglia in a monkey from group GFP plus LES showing substantial but subtotal reduction in staining in caudate (Caud) and putamen (Put). $C$, $F$, Lesioned basal ganglia in a monkey from group GDNF plus LES showing partial protection against the 6-OHDA lesion. The caudate, putamen, and globus pallidus (GP) are delineated by lines. $G-l$, High-power micrographs taken from $D-F$, respectively, at the locations indicated by the boxes. The arrowhead in $B$ shows needle track. Scale bars: (in A,D) A-F, $1 \mathrm{~mm}$; (in G) G-l,0.1 mm. VMAT2-IR pictures are not shown but look similar to the TH-IR figures.

similar between tasks. Behavioral deficits in the GDNF plus LES group 2 weeks after lesion may indicate 6-OHDAinduced damage to the DA terminals, which GDNF could not prevent, followed by a regenerative sprouting induced by GDNF. This mode of action would fit data obtained in the rodent intrastriatal 6-OHDA lesion model (Kirik et al., 2000a). Although the duration of the study was limited to 17 weeks, the implications for long-term efficacy are encouraging, because by 17 weeks, the GDNF plus LES group animals were behaving normally, whereas the GFP plus LES group remained significantly impaired.

\section{Pharmacological effects of GDNF on intact DA neurons}

The present study and previous work (Kirik et al., 2000a; Kordower et al., 2000; Georgievska et al., 2004) suggest that continuous GDNF delivery initially upregulates DA production and turnover in both rodents and primates. However, although this effect is rapidly saturated with increasing levels of GDNF in the rodent leading to downregulation [preventing behavioral recovery in lesioned animals (Georgievska et al., 2002)], TH enzyme levels remain upregulated in monkeys even with the high dose GDNF delivered in experiment 1 of the present study. It is unclear why monkey and rat brains respond differently to long-term GDNF delivery. Both the rodent and primate studies have used human GDNF, and there may be differences between the binding properties of human 


\section{GDNF+LES monkey}

GDNF-IR
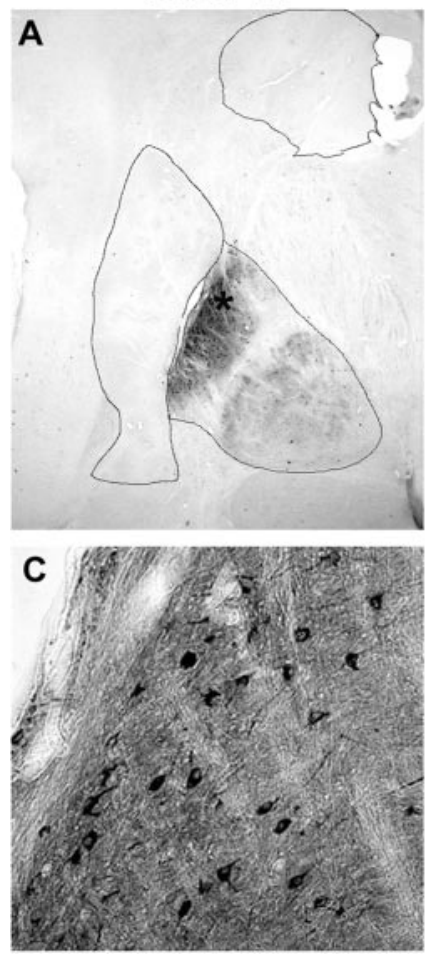

GFP-IR
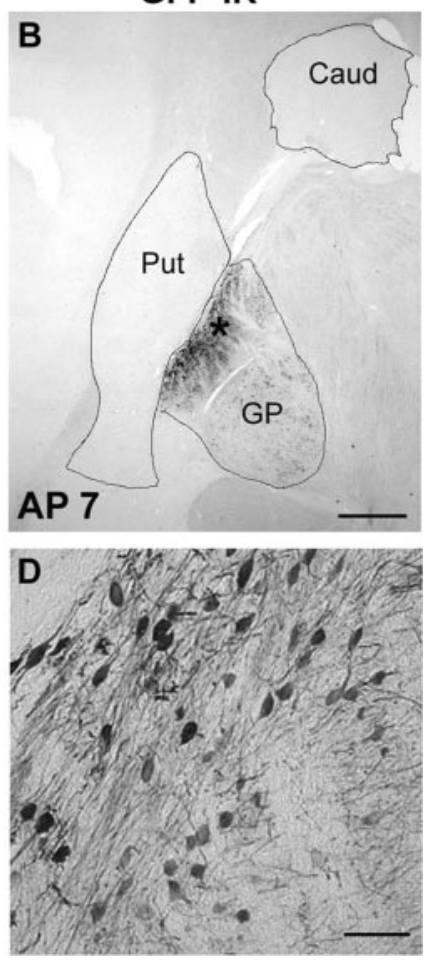

Figure 4. $\quad \operatorname{GDNF}-\mathbb{I R}(A, C)$ and GFP-IR $(B, D)$ reactivity in basal ganglia in a monkey from group GDNF plus LES. Scale bars: (in $B) A, B, 1 \mathrm{~mm}$; (in $C$ C $, D, 50 \mu \mathrm{m}$. Asterisks in $A$ and $B$ refer to locations of panels $C$ and $D$, respectively. Caud, Caudate; Put, putamen; GP, globus pallidus.

GDNF to primate and rodent receptors and/or species differences in the downstream events taking place within the activated DA neurons.

\section{Conclusions}

Highly elevated levels of TH activity and DA turnover and reduced DA levels in both hemispheres (experiment 1 of this study), together with the widespread distribution of GDNF to nontarget areas after injection of the high-expression vector (Eslamboli et al., 2003b), may cause a concern for the safety of such high levels of GDNF for patients, especially because high vector expression had negative behavioral effects (e.g., contralateral head positional bias) in intact animals (Eslamboli et al., 2003b). The possibility of behavioral and cognitive side effects makes external transgene regulation an absolute requirement for a GDNF-based gene therapy in PD. On the other hand, it was important to know whether the lower level of GDNF expression, which minimally affected DA function in normal animals, could reverse lesion-induced anatomical and behavioral deficits. The current data not only demonstrate that the lesioned DA system can be rescued by low levels of GDNF but also highlight the importance of regulating the levels of GDNF expression in patients, in which the administration of the minimum effective level of GDNF is the most desirable option.

\section{References}

Beck KD, Valverde J, Alexi T, Poulsen K, Moffat B, Vandlen RA, Rosenthal A, Hefti F (1995) Mesencephalic dopaminergic neurons protected by GDNF from axotomy-induced degeneration in the adult brain. Nature 373:339-341.

Bjorklund A, Kirik D, Rosenblad C, Georgievska B, Lundberg C, Mandel RJ
(2000) Towards a neuroprotective gene therapy for Parkinson's disease: use of adenovirus, AAV and lentivirus vectors for gene transfer of GDNF to the nigrostriatal system in the rat Parkinson model. Brain Res 886:82-98.

Burger C, Gorbatyuk OS, Velardo MJ, Peden CS, Williams P, Zolotukhin S, Reier PJ, Mandel RJ, Muzyczka N (2004) Recombinant AAV viral vectors pseudotyped with viral capsids from serotypes 1,2 , and 5 display differential efficiency and cell tropism after delivery to different regions of the central nervous system. Mol Ther 10:302-317.

Choi-Lundberg DL, Lin Q, Chang YN, Chiang YL, Hay CM, Mohajeri H, Davidson BL, Bohn MC (1997) Dopaminergic neurons protected from degeneration by GDNF gene therapy. Science 275:838-841.

Conway JE, Zolotukhin S, Muzyczka N, Hayward GS, Byrne BJ (1997) Recombinant adeno-associated virus type 2 replication and packaging is entirely supported by a herpes simplex virus type 1 amplicon expressing Rep and Cap. J Virol 71:8780-8789.

Deglon N, Tseng JL, Bensadoun JC, Zurn AD, Arsenijevic Y, Pereira dA, Zufferey R, Trono D, Aebischer P (2000) Self-inactivating lentiviral vectors with enhanced transgene expression as potential gene transfer system in Parkinson's disease. Hum Gene Ther 11:179-190.

Eslamboli A, Baker HF, Ridley RM, Annett LE (2003a) Sensorimotor deficits in a unilateral intrastriatal 6-OHDA partial lesion model of Parkinson's disease in marmoset monkeys. Exp Neurol 183:418-429.

Eslamboli A, Cummings RM, Ridley RM, Baker HF, Muzyczka N, Burger C, Mandel RJ, Kirik D, Annett LE (2003b) Recombinant adeno-associated viral vector (rAAV) delivery of GDNF provides protection against 6-OHDA lesion in the common marmoset monkey (Callithrix jacchus). Exp Neurol 184:536-548.

Georgievska B, Kirik D, Bjorklund A (2002) Aberrant sprouting and downregulation of tyrosine hydroxylase in lesioned nigrostriatal dopamine neurons induced by long-lasting overexpression of glial cell line derived neurotrophic factor in the striatum by lentiviral gene transfer. Exp Neurol 177:461-474.

Georgievska B, Kirik D, Bjorklund A (2004) Overexpression of glial cell linederived neurotrophic factor using a lentiviral vector induces time- and dose-dependent downregulation of tyrosine hydroxylase in the intact nigrostriatal dopamine system. J Neurosci 24:6437-6445.

Gill SS, Patel NK, Hotton GR, O'Sullivan K, McCarter R, Bunnage M, Brooks DJ, Svendsen CN, Heywood P (2003) Direct brain infusion of glial cell line-derived neurotrophic factor in Parkinson disease. Nat Med 9:589-595.

Kirik D, Rosenblad C, Bjorklund A, Mandel RJ (2000a) Long-term rAAVmediated gene transfer of GDNF in the rat Parkinson's model: intrastriatal but not intranigral transduction promotes functional regeneration in the lesioned nigrostriatal system. J Neurosci 20:4686-4700.

Kirik D, Rosenblad C, Bjorklund A (2000b) Preservation of a functional nigrostriatal dopamine pathway by GDNF in the intrastriatal 6-OHDA lesion model depends on the site of administration of the trophic factor. Eur J Neurosci 12:3871-3882.

Kirik D, Georgievska B, Bjorklund A (2004) Localized striatal delivery of GDNF as a treatment for Parkinson disease. Nat Neurosci 7:105-110.

Kordower JH, Palfi S, Chen EY, Ma SY, Sendera T, Cochran EJ, Mufson EJ, Penn R, Goetz CG, Comella CD (1999) Clinicopathological findings following intraventricular glial-derived neurotrophic factor treatment in a patient with Parkinson's disease. Ann Neurol 46:419-424.

Kordower JH, Emborg ME, Bloch J, Ma SY, Chu Y, Leventhal L, McBride J, Chen EY, Palfi S, Roitberg BZ, Brown WD, Holden JE, Pyzalski R, Taylor MD, Carvey P, Ling Z, Trono D, Hantraye P, Deglon N, Aebischer P (2000) Neurodegeneration prevented by lentiviral vector delivery of GDNF in primate models of Parkinson's disease. Science 290:767-773.

Lotharius J, Barg S, Wiekop P, Lundberg C, Raymon HK, Brundin P (2002) Effect of mutant alpha-synuclein on dopamine homeostasis in a new human mesencephalic cell line. J Biol Chem 277:38884-38894.

Lu X, Hagg T (1997) Glial cell line-derived neurotrophic factor prevents death, but not reductions in tyrosine hydroxylase, of injured nigrostriatal neurons in adult rats. J Comp Neurol 388:484-494.

Mandel RJ, Spratt SK, Snyder RO, Leff SE (1997) Midbrain injection of recombinant adeno-associated virus encoding rat glial cell line-derived neurotrophic factor protects nigral neurons in a progressive 6-hydroxydopamine-induced degeneration model of Parkinson's disease in rats. Proc Natl Acad Sci USA 94:14083-14088.

Marshall JW, Baker HF, Ridley RM (2002) Contralesional neglect in mon- 
keys with small unilateral parietal cortical ablations. Behav Brain Res 136:257-265.

Milton AL, Marshall JW, Cummings RM, Baker HF, Ridley RM (2004) Dissociation of hemi-spatial and hemi-motor impairments in a unilateral primate model of Parkinson's disease. Behav Brain Res 150:55-63.

Nutt JG, Burchiel KJ, Comella CL, Jankovic J, Lang AE, Laws Jr ER, Lozano AM, Penn RD, Simpson Jr RK, Stacy M, Wooten GF (2003) Randomized, double-blind trial of glial cell line-derived neurotrophic factor (GDNF) in PD. Neurology 60:69-73.

Peden CS, Burger C, Muzyczka N, Mandel RJ (2004) Circulating anti-wildtype adeno-associated virus type 2 (AAV2) antibodies inhibit recombinant AAV2 (rAAV2)-mediated, but not rAAV5-mediated, gene transfer in the brain. J Virol 78:6344-6359.

Reinhard Jr JF, Smith GK, Nichol CA (1986) A rapid and sensitive assay for tyrosine-3-monooxygenase based upon the release of $3 \mathrm{H} 2 \mathrm{O}$ and adsorption of [3H]-tyrosine by charcoal. Life Sci 39:2185-2189.

Rosenblad C, Kirik D, Devaux B, Moffat B, Phillips HS, Bjorklund A (1999) Protection and regeneration of nigral dopaminergic neurons by neurturin or GDNF in a partial lesion model of Parkinson's disease after administration into the striatum or the lateral ventricle. Eur J Neurosci 11:1554-1566.

Rosenblad C, Gronborg M, Hansen C, Blom N, Meyer M, Johansen J, Dago L, Kirik D, Patel UA, Lundberg C, Trono D, Bjorklund A, Johansen TE (2000a) In vivo protection of nigral dopamine neurons by lentiviral gene transfer of the novel GDNF-family member neublastin/artemin. Mol Cell Neurosci 15:199-214.

Rosenblad C, Kirik D, Bjorklund A (2000b) Sequential administration of GDNF into the substantia nigra and striatum promotes dopamine neuron survival and axonal sprouting but not striatal reinnervation or functional recovery in the partial 6-OHDA lesion model. Exp Neurol 161:503-516.
Rosenblad C, Georgievska B, Kirik D (2003) Long-term striatal overexpression of GDNF selectively downregulates tyrosine hydroxylase in the intact nigrostriatal dopamine system. Eur J Neurosci 17:260-270.

Sauer H, Rosenblad C, Bjorklund A (1995) Glial cell line-derived neurotrophic factor but not transforming growth factor beta 3 prevents delayed degeneration of nigral dopaminergic neurons following striatal 6-hydroxydopamine lesion. Proc Natl Acad Sci USA 92:8935-8939.

Stephan H, Baron G, Schwerdtfeger WK (1980) The brain of the common marmoset (Callithrix jacchus): a stereotaxic atlas. Berlin: Springer.

Sullivan AM, Opacka-Juffry J, Blunt SB (1998) Long-term protection of the rat nigrostriatal dopaminergic system by glial cell line-derived neurotrophic factor against 6-hydroxydopamine in vivo. Eur J Neurosci 10:57-63.

Tomac A, Lindqvist E, Lin LF, Ogren SO, Young D, Hoffer BJ, Olson L (1995) Protection and repair of the nigrostriatal dopaminergic system by GDNF in vivo. Nature 373:335-339.

West MJ (1999) Stereological methods for estimating the total number of neurons and synapses: issues of precision and bias. Trends Neurosci 22:51-61.

Winkler C, Sauer H, Lee CS, Bjorklund A (1996) Short-term GDNF treatment provides long-term rescue of lesioned nigral dopaminergic neurons in a rat model of Parkinson's disease. J Neurosci 16:7206-7215.

Xu L, Daly T, Gao C, Flotte TR, Song S, Byrne BJ, Sands MS, Parker-Ponder K (2001) CMV-beta-actin promoter directs higher expression from an adeno-associated viral vector in the liver than the cytomegalovirus or elongation factor 1 alpha promoter and results in therapeutic levels of human factor X in mice. Hum Gene Ther 12:563-573.

Zolotukhin S, Byrne BJ, Mason E, Zolotukhin I, Potter M, Chesnut K, Summerford C, Samulski RJ, Muzyczka N (1999) Recombinant adenoassociated virus purification using novel methods improves infectious titer and yield. Gene Ther 6:973-985. 